\title{
Physicochemical and microbial attributes of organic infused beef cuts (longissmus dorsi).
}

\begin{abstract}
This study was carried out to determine the effect of infusing food grade organic acids on the shelf life of fresh beef kept at refrigeration temperature of 5C. Citric, lactic, acetic and tartaric acids were infused individually in concentrations of $0.5,0.75$ and $1.00 \%$ into fresh beef slices. Infusion was carried out under pulled of $29.5 \mathrm{in}$. $\mathrm{Hg}$. for $20 \mathrm{~min}$. Samples were dropped dried and stored at 5C for 28 days. $\mathrm{pH}$, water activity, total plate count (TPC), thiobarbaturic acid values, Hunter color values and instrumental texture were determined. The $\mathrm{pH}$ value of the treated samples dropped from the initial $\mathrm{pH}$ of 5.30 (untreated) to 4.20 4.47 and the TPC values were lower than 107 colony-forming units/g on day 16, 20 and 28 in samples treated with $0.5,0.75$ and $1.00 \%$ acids, respectively. The instrumental texture of the treated samples was harder upon treatment, which decreased gradually during storage period. The maximum shelf life of treated beef was extended to 12-24 days and citric acid in concentration of $1.00 \%$ gave the best effect.
\end{abstract}

Keyword: Physicochemical attributes; Microbial attributes; Organic acids; Infused beef cuts. 